\title{
Causal Recipes for Cultural Adaptation of Romanian Football Players
}

\author{
Daniel Lovin \\ lovin daniel@hotmail.com \\ Alexandru Capatina \\ alexandru.capatana@ugal.ro \\ Dunarea de Jos University of Galati, Romania \\ Denis Bernardeau-Moreau \\ denis.bernardeau-moreau@,univ-lille.fr \\ University of Lille, France
}

\begin{abstract}
Most of the Romanian football players who left the internal championship and signed contracts abroad have failed in their attempt to culturally adapt to a new club. The purpose of this paper is to explore the extent to which Romanian football players, who left the internal competition, are aware of the necessity of cultural adaptation in the host countries. Employing a fuzzy set qualitative comparative analysis (fsQCA - Berg, Dirk, Rihoux and Ragin 2008), this study proposes a configurational approach of Cultural Intelligence skills (Cognitive, Meta-Cognitive, Motivational and Behavioural), affecting the expected outcome: the level of adaptation in the host club. Findings reveal that a causal configuration of antecedent conditions (Cognitive, Meta-Cognitive, Motivational) are sufficient conditions to reach the outcome.
\end{abstract}

Key words: Cultural intelligence, adaptation, globalization, sport management, cultural organization, interculturality

\section{Cultural adaptation in sport organization}

Football has become a global business being a pretty risky business. In the last period many Romanians football players who left the intern competition to play abroad, in a different cultural context, failed in their attempt to adapt. This study uses a fuzzy set qualitative comparative analysis to find if the level of the adaptation of the Romanians football players who play in a foreign country is influenced by the cultural intelligence skills.

We live in a world where transportation and travel have become cheaper than ever. In addition, destinations are multiple and travel distances are longer and longer. Technology is developing very fast and this aspect facilitates the mobility of individuals (Westerbeek, Smith 2003). So, all of these things have made people interact more and more often with other people, who, even if they seem to be like us, they think differently and behave differently and sometimes these differences put people in trouble (Erez, Earley 1993).

Many times, cultural differences lead to difficulties of understanding and in some situations cultural differences can lead to conflict. The culture influences the individual and the group efficiency (Bandura 1986). However, it has been found that individuals with intelligence or high social intelligence have failed to adapt in a multicultural context (Erez, Ang 2003). Thus, researchers defined the concept of cultural intelligence. This concept tries to explain why the performances of the individuals differ in different cultures.

This multiculturalism is perhaps the easiest to observe in sport in general, but especially in football, which is the most widely publicized sport in the world. Moreover, sport has become a business, and business people try to get the most out of the people they run, regardless of the cultural context they come from. This concept of cultural intelligence was titled by Earley and Ang.

In the world the number of multicultural teams is growing and the number of managers who fail in a new culture is growing. Thus, a new question could be asked: is intelligence a one- 
dimensional concept or is it a multidimensional concept? It seems that the concept of intelligence is still incomplete. To say of one culture or another that it is more culturally intelligent is totally inadequate (Hall 1987). This concept cannot be attributed to a group of individuals as a label.

However, it seems logical that individuals from a developed country from an economic point of view and with a higher standard of living, have the opportunity to interact more often with other cultures. For example, people in cities like Paris, London, Barcelona or Rome often interact with people who belong to other cultures because, on the one hand, their cities are very touristy and on the other because they live in a country with a higher standard of living, with a very wellestablished transportation system, they earn high wages and travel to other parts of the world where they can meet people from other cultures. Intelligence comes with experience and these people can use their experience gained when they interact with people from other cultures. However, there are countries in the world with only one major ethnic group, low socio-economic development and not too touristic. It is obvious that people living in such countries are less likely to interact with people from other cultures and their multicultural experience is reduced.

Erez and Ang define cultural intelligence as "the ability of an individual to successfully adapt to other cultural norms, foreign to the culture to which he belongs". These cultural differences influence the behaviour at work. When people interact with others who belong to other cultures, many of them misunderstand the moods and emotions of others. Cultural intelligence means for an individual to act quickly, correctly and at the right time, in a context that is unknown to him.

Sternberg and Kaufman (1998) state that intelligence can vary according to culture. For example, in India and other Asian countries (with the exception of China) the notion of intelligence is strongly influenced by Hindu and Buddhist philosophy. In these cultures, the determination, the mental effort, the feelings and the opinions are seen as part of the intelligence (Das 1994). On the other hand, Americans consider general intelligence as: solving practical problems, verbal skills and social skills (Sternberg and Kaufman 1998). To continue this comparison, on the one hand Asian and African cultures focus too much on social intelligence and on human relations and on the other hand, Western cultures focus on cognitive intelligence and on the ability to reach individual goals (Ruzgis and Grigorienko 1994).

The concept of cultural intelligence has emerged because the phenomenon of globalization is increasingly present in companies whether they are sportive or not. Then, with regard to sports organizations, we can see that globalization is increasingly present in sport. At the same time, this concept emerged because it was necessary to find explanations for situations in which people with higher abilities could not adapt in a culturally different environment. Thus, it seems that general intelligence, social intelligence and emotional intelligence were not sufficient for adaptation in another culture. This adaptation requires different abilities than those used in a context that is familiar (Erez, Son 2003).

A first step towards easier integration would be to learn the modality in which individuals from a foreign culture act. Then, a culturally intelligent individual will always have (in this ability to understand other people's ways of acting), the motivation to act and the ability to respond according to the context in which they find themselves. A culturally intelligent person has the ability to acquire new behaviours that are necessary for integration into a new culture (Erez and Earley 1993).

Culture is closely linked to society and researchers have defined culture in different ways. At the same time, cultural intelligence requires a logical analysis of the events occurring in the social environment, and on the basis of these logical reasoning the individual must put into practice culturally intelligent behaviour. Then, the individual should not be influenced by preconceived ideas (Hall 1976).

Generally, individuals refuse tasks and difficult situations that they consider to exceed their capacity. Effective thinking occurs when an individual chooses the task that has the greatest chance of success and eliminates tasks that outperform his or her abilities or group capabilities. Individuals always look for situations that give them pleasure and try to avoid situations that create discomfort, but this attitude is generically perceived as a form of intelligence (Thorndike 
1920). This situation is not applicable in the field of cultural intelligence, because the adaptation in a different cultural context involves facing certain obstacles and discomforts. It's almost impossible to adapt without making the discomfort. A culturally intelligent person understands this aspect and will not avoid this kind of situations, but will try to use the feedback obtained to be more adaptable (Bandura 1997).

The ability to assess effectiveness is paramount at the individual level as well as at the group level as well. Thus, group members and managers need to know what to choose, how much effort to put, and how persevering they should be when they fail. The power of groups, organizations and nations is especially related to the collective capacity of individuals (Bandura 1997).

Until now, is not yet so clear how the social environment could influence a person's effectiveness is how is it possible that an individual could have success in one cultural environment and not in another. However, the cultural environment also influences individual and collective effectiveness. Moral and social norms play a very important role in the adaptation of individuals to a new culture. These rules and norms may differ from one culture to another and may conflict with the information an individual possesses from his /her culture (Earley and Ang, 2003).

Nowadays football is characterized by a meeting between cultures. Organizational culture means to share value and beliefs which could influence the habits, attitudes and behaviors of the member of the organization (Schein, 2010). The members of the organization (managers, staff, athletes) need to understand he tradition and the history which are part of the sport organization and have to find a way to use the with a positive impact.

Organization culture shows how an organization does things. Every sport organization has an organizational culture, but some cultures are stronger than others. By example, an organization with a solid culture will always find a way to win because the success is an integral part of their identity (Bettinger, 1989). Many Italian or Spanish football clubs are obsessed by victory and are willing even to go in debt to do achieve that. The smart application of sport culture requires the understanding of how the culture was created, transmitted and maintained (Hoye, Smith, Nicholson, Stewart, 2015).

\section{Cognitive intelligence}

Cultural intelligence is a multidimensional concept formed by four dimensions : cognitive crosscultural skills, metacognitive cross-cultural skills, motivational skills and behavioural skills (Ang 2007). Even if it seems paradoxical, when an individual has to adapt in a culturally different environment, he often has to forget what he has learned before. Many times, the information that comes in the new cultural context comes into conflict with the information the individual has about his / her culture and this conflict can affect the process of adaptation. Thus, specialists consider that for an individual is better sometimes to forget what he has learned (Thorndike, 1920). This idea could be compared as a renaissance that will help the individual adapt in a new cultural environment.

The cognitive part of cultural intelligence tries to find the answers to the three questions:

1. What are the means that can be determined who am I and who are the others?

2. How is this person and why is she is like that?

3. How can people be and why?

Answers to these questions help the individual to understand the new culture and to behave appropriately in human relationships.

Moving to a new culture is a difficult action that takes the individual to surpass his comfort zone. This adaptation requires abilities that are not found in other forms of intelligence, because many aspects differ from previous situations and because social interactions are different. In addition, many times, the rules that are learned in one culture do not help successfully adapt to another culture, and yet, in addition, they make adaptation more difficult. Adaptation into a new cultural climate requires a complete set of cognitive abilities (Earley, Son 2003) 


\section{Metacognitive intelligence}

The metacognitive part of the cultural intelligence refers to necessary strategies for reaching a goal and to the adaptation to the new information which can appear when someone's is trying to solve some tasks. The metacognitive skills are superior judgments that which help a person to reflect about his or her personal actions and thoughts as well as those of other people (Erez and Ang 2003).

A metacognitive experience means to understand that a task or an activity is hard to do, hard to understand or to interpret how things can evolve. An important role in the metacognitive intelligence is played by the experience. The previous experiences help people to take efficient decisions in a multicultural context (Schraw and Moshman, 1995). Moreover, metacognitive intelligence means to understand how a person can react in some situation. The metacognitive abilities help to understand and predict how a person will behave (Flavell 1987).

\section{Motivational intelligence}

Cultural intelligence reflects the personal image of the individual, and this image makes the individual motivated or not motivated to adapt in a new cultural environment (Erez and Earley 1993). In turn, the motivational part of cultural intelligence is formed by three elements: selfimprovement, efficiency and perseverance. Self-improvement refers to the desire of the individual to be better and to have better results. Self-improvement is the ability of an individual to understand their personal ability or the ability of others to achieve a certain level of performance.

Generally, individuals refuse tasks and difficult situations that they consider to exceed their capacity. Effective thinking occurs when an individual chooses the task that has the greatest chance of success and eliminates tasks that outperform his or her abilities or group capabilities (Ng, Earley 2006).

The concept of self-improvement involves achieving one's goals, the ability to verbally persuade and mastering psychological factors. Knowledge of psychological factors is important because this ability involves the assessment of a person's condition such as fatigue, stress, anxiety. These factors influence a person's performance, and for example a tired person might not be effective. The ability to assess effectiveness is paramount at the individual level as well as at the group level as well. Thus, group members and managers need to know what to choose, how much effort to put, and how persevering they should be when they fail. The power of groups, organizations and nations is especially related to the collective capacity of individuals (Bandura 1997).

For example, an individual who is learning a new foreign language, has a good memory and can reproduce sound well. Even so, this person may not fit into a new cultural environment, because she may be hesitant when she speaks in public and because she is afraid of being ashamed (Earley, Son 2003).

\section{Behavioural intelligence}

Cultural intelligence requires knowing what to do and when to do and at the same time having the desire to persevere and to make various efforts. In addition, cultural intelligence requires having the right behaviour for a particular situation. If a person lacks specific behaviour, he must have the ability to acquire appropriate behaviour if he wishes to have a superior cultural intelligence.

Cultural intelligence reflects a person's ability to acquire new behaviours specific to another culture. Difficulties in acquiring a new foreign language and mastering an appropriate pronunciation may be important elements in cultural intelligence. People who do not have skills in acquiring a foreign language or do not want to learn a new language, at least at a reasonable level, will have a reduced level of cultural intelligence (Ang 2007).

In addition, another element that is part of the behavioural part of cultural intelligence is the constant perseverance in a period of time. Perseverance is necessary to acquire new abilities such as learning a foreign language. A person with a good level of cultural intelligence always has the 
desire to learn new behaviours. Then, such a person is able to control his non-verbal language, which means managing his emotions and physical presence (Dunette, 1976).

Cultural intelligence involves the analysis of information that individuals receive. However, cultural intelligence presupposes the understanding and use of acquired information, but also the way in which this information guides the actions of the individual in various situations. A culturally intelligent person has a great capacity for storing information and analysing new information (Earley, Ang, 2003).

\section{Method}

One of the most influential recent novelty in the social science is this Qualitative comparative analysis (Thiem, Dusa 2013). It supposes a different mix of conditions which offers different possibilities for the causal complexity behind a phenomenon (Berg - Schlosser, 2008). One result can be provoked by a variety of conditions, which are all treated with equal importance (Ragin 1987). Moreover, this kind of researches and statistics are used more and more in different fields of activities where teamwork is cruial. This method (fsQCA) has also begun to be used in football. Thus, some Swiss researchers (Kaufmann, 2014) have used this method to find and suggest to the manager of the Swiss national football team the best solution for the pair of central backs. For a number of six players, the researchers have chosen two central back based on the number of minute played, goals conceded and on the other center back teammate (Kaufmann, 2014). This method (QCA) is a research technique which close the gaps between qualitative and quantitative analyses (Rihoux and Ragin, 2009). This method creates the possibility to analyse how multiple causal configurations affect a result (Ragin, 2014). This method indicates the conditions that are enough (but not necessary) to reach an outcome. QCA shows how causal configurations bring to a result (Woodside, 2010).

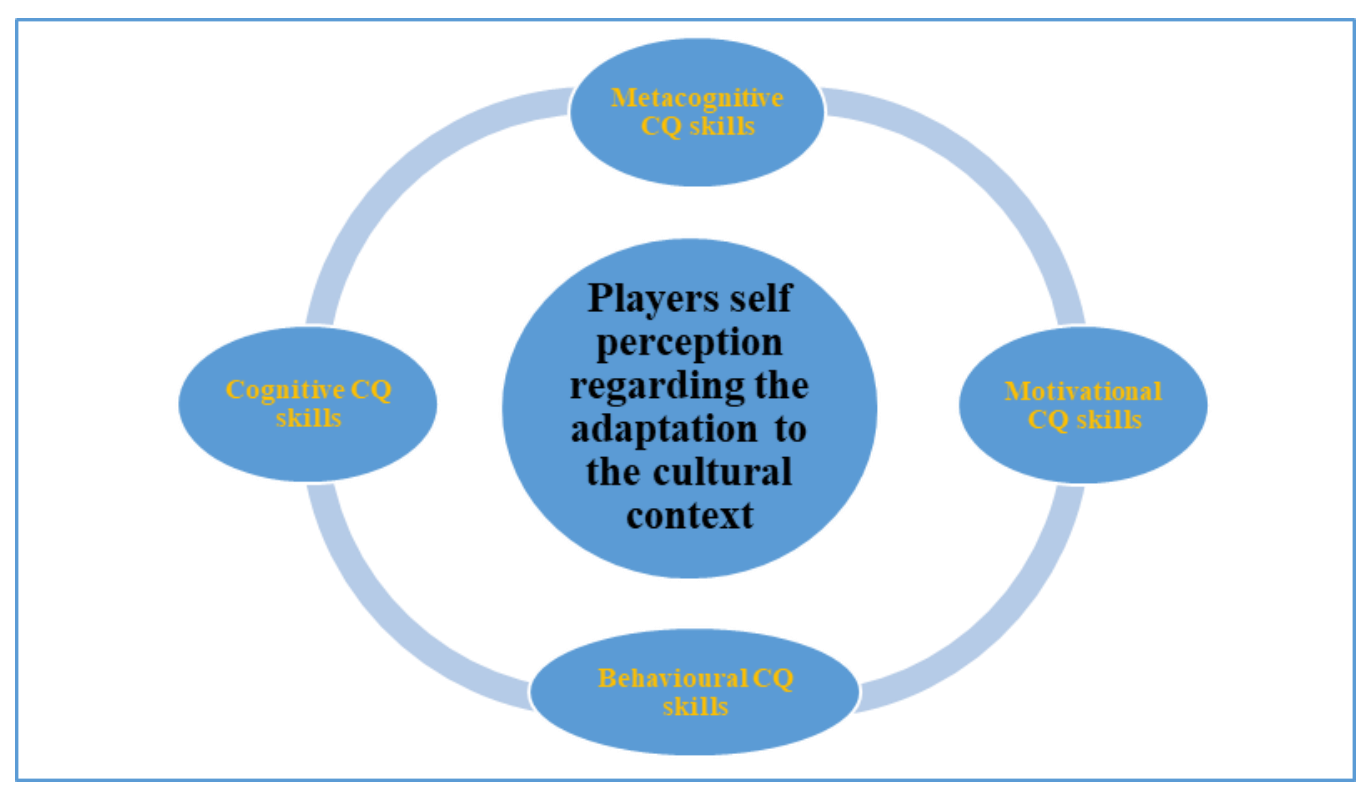

Fig. 1 Conceptual model (Bücker, Furrer, Lin, 2015)

In our research we sent the questionnaire to 10 Romanians football players who played abroad in the last decade in different Europeans countries. In the last decade over thirty Romanians players left the country to play abroad, and their vast majority failed abroad and come back in Romania. The purpose of this paper is to understand and evaluate the importance of possessing cultural intelligence skills in sport management. Employing a fuzzy qualitative comparative analysis, the study examines how cultural intelligence influences the adaptation and the efficiency of Romanian football players in another cultural context. We consider the culture plays an important role in the efficiency of a sport organization. Moreover, the cross-cultural skills of the managers, 
of the staff and of the players makes the difference between the success and the loss on the pitch and out of the pitch.

The antecedent conditions used in this fsQCA research are the four components of the cultural intelligence: metacognitive skills, cognitive skills, motivational skills and behavioural skills and the outcome is the players self-perception regarding the adaptation to the cultural context.

In a multicultural context, many businessmen and stakeholders who are watching football does not understand that cultural difference may be the cause of the failure. Players and managers are not machines and they need to put in practice cross cultural skills to perform in a culture which is different from the mother culture. This study shows how causal variables (metacognitive skills, cognitive skills, motivational skills, behavioural skills) influence the perception regarding the adaptation to the cultural context. A player who adapted in a different cultural context could be perceived like an intelligent cultural player and very probably will easily adapt in another context too (Bücker, Furrer, Lin 2015).

The questionnaire of the cultural intelligence scale has 23 items which cover the four dimensions of the cultural intelligence: metacognitive CQ items (eg. "I adjust my cultural knowledge as I interact with people from a culture that is unfamiliar to me"); cognitive CQ items (eg. "I know the rules of grammar of others language); motivational CQ items (eg. "I'm confident that I can socialize with locals in a culture that is unfamiliar to me"); behaviour CQ items (eg. "I change my nonverbal behaviour when a cross cultural interaction requires it"). In addition, the questionnaire contains three more questions: one to find the perception of the adaptation level to the host club, another item to find the nationality of the players and the last to find the country where they played. All the players surveyed are from Romania and played in the clubs in Europe.

This questionnaire has been designed and posted online on Google Forms in order to identify the players perception regarding the adaptation to the cultural context. They are assessed through a five-point Likert scale : from 1 - not at all to 5 - to a very great extent. fsQCA method requires a calibration process to assess the degrees to which the 10 cases belong to different membership levels. In this way, we turned the values from the Likert scale (1 to 5) in values ranging from 0 to 1. Table 1 reflects the calibration scale, which has been applied to the antecedent conditions and outcome.

Table 1 - Calibration of scales

\begin{tabular}{lll}
\hline Scale point & Fuzzy-set value & Membership \\
\hline Strongly agree/Very probably & 1 & Fully in \\
Agree/Probably & 0.75 & More in than out \\
$\begin{array}{l}\text { Neither agree or disagree/ } \\
\text { Possibly }\end{array}$ & 0.5 & Cross-over (neither in nor out) \\
$\begin{array}{l}\text { Disagree/Probably not } \\
\text { Strongly disagree/Definitely not }\end{array}$ & 0.25 & More out than in \\
\hline
\end{tabular}

(Ragin, 2014)

Table 2 outlines the four antecedent conditions derived from the research model, revealing the players' interest for Cultural Intelligence skills, the outcome (how they perceive the adaptation to their new clubs). 


\begin{tabular}{|c|c|c|c|c|c|}
\hline \multirow[b]{2}{*}{ Player } & \multicolumn{4}{|c|}{ Table 2 - Calibrated fuzay-sets of the 10 cases } & \multirow[b]{2}{*}{ OUTCOME } \\
\hline & MC & COG & MOr & BEH & \\
\hline 1 & 0.7 & 0.63 & 0.76 & 0.68 & 0.5 \\
\hline 2 & 0.95 & 0.67 & 0.88 & 0.72 & 1 \\
\hline 3 & 0.85 & 0.6 & 0.84 & 0.56 & 0.75 \\
\hline 4 & 0.8 & 0.83 & $0.8 B$ & 0.68 & 0.75 \\
\hline 5 & 1 & 0.8 & 1 & 1 & 1 \\
\hline 6 & 0.85 & 0.6 & 0.88 & 0.92 & 1 \\
\hline 7 & 0.95 & 0.77 & 1 & 0.56 & 0.5 \\
\hline 8 & 0.95 & 0.5 & 0.68 & 0.56 & 0,5 \\
\hline 9 & 0.75 & 0.63 & 0,92 & 0.4 & 1 \\
\hline 10 & 1 & 0.5 & 0.64 & 0.84 & 1 \\
\hline
\end{tabular}

\section{Findings}

The results show that the causal recipes are enough for the adaptation in a different cultural context. So, eight cases are situated over the XY plot and only two cases are under, but close to the plot. The complex solution suggested by the algorithm is metacognitive - cognitive motivational. It means that these three sides of cultural intelligence are enough for the adaptation. If Pareto principle says that $80 \%$ of the effects come from $20 \%$ of the causes, in this case we can observe that $75 \%$ of cross-cultural skills determines $100 \%$ of the adaptation in another cultural context. Moreover, this solution suggests that football players firstly think (metacognitive and cognitive skills), than they are motivated by certain factors and in the last they act. The behaviour is a consequence of the others three sides and it cannot be changed without changing the thinking or without motivation. In a multicultural context, the athletes who want to adapt, need to use their metacognitive and cognitive skills and change their thinking.

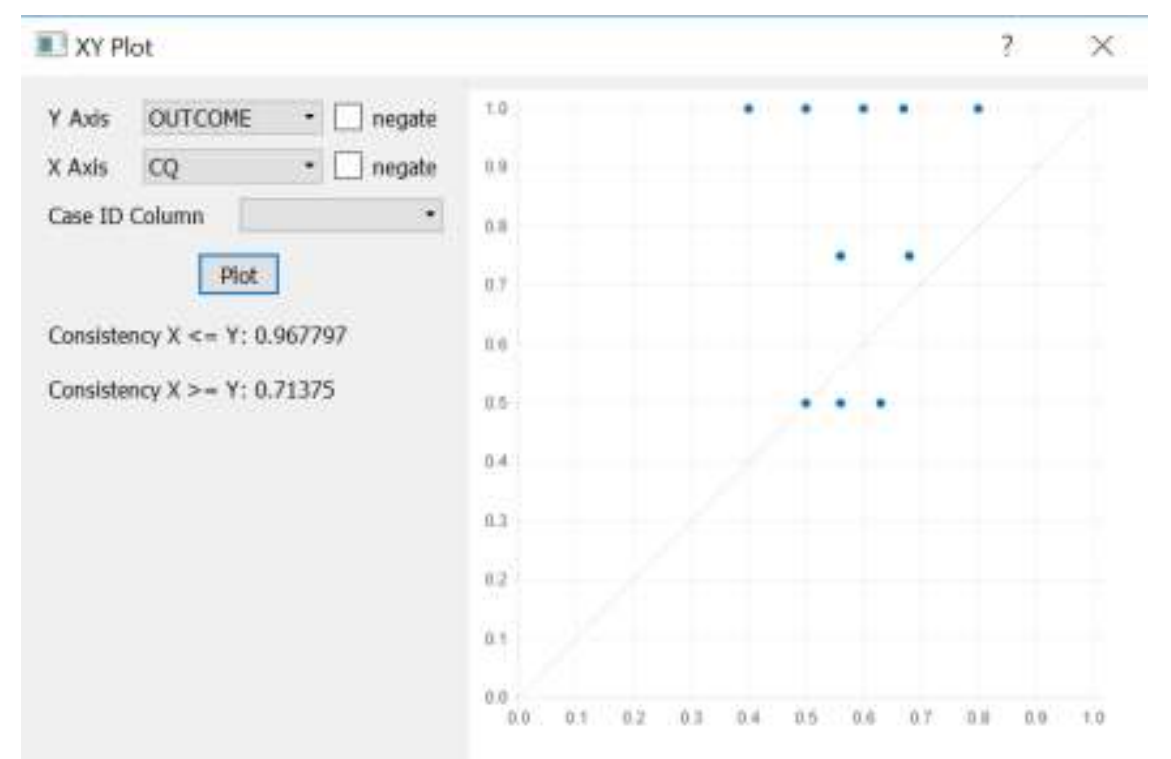

Figure 2 - Distribution of cases within XY Plot graph

The complex solution (Table 3) reflects that three cultural intelligence skills involved in the research framework are powerful predictors of the outcome: footbal players capability to adapt to new clubs abroad, as the consistency score value (0.93) is very high. 
Table 3 -Complex solution

\begin{tabular}{|l|l|l|l|}
\hline \multicolumn{4}{|c|}{ Complex solution } \\
\hline Frequency cutoff: & 1 & \multicolumn{3}{|l|}{} \\
\hline \multirow{2}{*}{ Consistecy cutoff: } & 0,967797 & Unique coverage & consistency \\
\cline { 2 - 4 } & Raw coverage & 0.75626 & 0.930769 \\
\hline MC*COG*MOT & 0.75625 & & \\
\hline Solution coverage: & 0.75625 & \multicolumn{3}{|l}{} \\
\hline $\begin{array}{l}\text { Solution } \\
\text { consistency: }\end{array}$ & 0.930769 & & \\
\hline
\end{tabular}

In this situation, a single pathway led to the expected outcome, so the principle of equifinality, which highlight various pathways - combinations of antecedent conditions could achieve the outcome, is not supported. The only solution to achieve a good level of adaptation in one other cultural environment is the possession of the three dimensions of cultural intelligence: metacognitive, cognitive and motivational. Other combinations of these four dimensions are not indicated by this method.

\section{Discussion, conclusions, limitations and future research}

Nowadays, the world is more intercultural than ever and many sport organisations became a globalised business. Managers, staff and players need to take in consideration the cultural differences and need to put in practice cross cultural skills. In this world, the football players have the possibility to play abroad, in country which the culture is different from their native culture. It doesn't matter the country, the region, the club or the level of the football, the culture and the organization culture of that club will influence the adaptation of the players and his efficiency on the field. For the managers and for the players is beneficial to understand that the cultural differences affect the efficiency of the organization. The managers and the football players need to put in practice their cross-cultural skills, the metacognitive skills, cognitive skills and their motivation in order to have an appropriate behaviour to the new cultural environment.

The fsQCA method shows that three antecedents' conditions are sufficient for the adaptation in a cultural context. These conditions are metacognitive skills, cognitive skills and motivational. The behavioural skills are not included because the behaviour cannot be influenced without the other three skills. In order to change the behaviour, you have to change first the way of thinking and then to be motivated to act. Even the questionnaire is applied to football players, we consider that the solution can also be applied in non-sports organization.

The limitations of this study are as follows: first, the data were gathered for only 10 Romanians football players, which limits the generalizability of our findings. This small number of football players is reduced because in the last period not many football players left the country to play abroad and on the other hand because it is not so easy to get in touch with them. Second, this study examines only four antecedents of the outcome, which could be challenged by other researchers and practitioners.

Even the questionnaire was applied to a sample of athletes, this solution could be adapted in other business areas. No matter the field of the activity, a human being who wants to adapt in a multicultural context needs to take in consideration the cultural differences and to put in practice his cross-cultural skills.

Concerning the Romanian culture, it is interesting to figure out if the cultural Romanian elements don't favour the adaptation of Romanian football players. At the same time, it will be interesting to find out if it is difficult for foreign players to adapt in Romania. If it is difficult to adapt in Europe where the differences aren't so pronounced, it would be logical that the adaptation on others continents will be harder. Moreover, a study should be done to find out what we can do to improve the cross-cultural skills to adapt in different sport organization. To have the best results, this improvement has to be taken into account from the youngest ages. 
Therefore, in the near future not only, the Romanians football players but even the Romanian people who want to adapt abroad in a new cultural context, need to take in consideration the cultural differences and put in practice their cross-cultural skills in order to be efficient at their workplace. Not least, it is important to underline that we should focus more on monocausal explanations of group performances (Kaufmann 2014).

\section{References}

1. Ang, S. et all (2007) - Cultural intelligence: its measurement and effects on cultural judgment and decision making, cultural adaptation and task performance. Management and Organization Review 3: 335-371.

2. Ang $S$ and Van Dyne L (2008) Handbook of cultural intelligence: Theory, measures and applications. Armonk, NY: M.E. Sharpe.

3. Bandura, A. (1997) - Self efficacy: the exercise of control. Ney York: W.H. Freeman and Company;

4. Bandura, A (1986)-Social foundations of thoughts and action: a social cognitive theory, Englewood Cliffs, N.J.:Prentice hall;

5. Berg S., Dirk, G., Rihoux, B. and Ragin, C. (2008) -Qualitative Comparative Analysis (QCA) as an Approach" In Configurational comparative methods. Qualitative Comparative Analysis (QCA) and related techniques, eds. RIHOUX, Benoit and Charles Ragin. Thousand Oaks and London: Sage, 1-18.

6. Bettinger, C. (1989) - Use corporate culture to trigger high performance. Journal of business strategy, 10(02) $38-42$;

7. Bücker, J., Furrer, O., \& Lin, Y. (2015). Measuring cultural intelligence (CQ) A new test of the CQ scale. International Journal of Cross Cultural Management, 15(3), 259-284.

8. Das, J.P. (1994) - Eastern views of intelligence, ed Encyclopedia of human intelligence 391, New York: Macmillan;

9. Denison, D. and Mishra A., - Toward a theory of organizational culture and effectiveness. Organizational science, 6 , 204-224;

10. DeSensi, J. T. (1994) - Multiculturalism as an issue in sport management. Journal of Sport Management, 8(1), 63-74;

11. Dunette, M. P. (1976) - Aptitudes, abilities and skill, in M.D. Dunette ed. Chicago: Rand McNally;

12. Earley, M. and Ang, S. (2003) - Cultural intelligence, Easter views of intelligence, Stanford, California, Stanford Unviersity Press;

13. Erez, M.and Earley, P.C. (1993) - Culture, self-identity and work: New York, Oxford University Press;

14. Fiss, P. C. (2007). A set-theoretic approach to organizational configurations. Academy of Management Review, 32(4), 1180-1198.

15. Flavell, J.H. (1987) - Speculations about the nature of development of metacognition, Hillsdale, N.J. : Lawrence Erlbaum;

16. Frontiera, J. (2010) - Leadership and organizational culture transformation in professional sport, Journal of Leadership and organizational Studies, 17: 171-186;

17. Hall, E.T. (1976) - Beyond culture, New York: Doubleday;

18. Kaufmann, D. (2014). Assessing collective defensive performances in football: A Qualitative Comparative Analysis of central back pairs;

19. Ng KY and Earley CP (2006) Culture and intelligence: Old constructs, new frontiers. Group \& Organization Management 31: 4-19;

20. Ragin, C. C. (2014). The comparative method: Moving beyond qualitative and quantitative strategies. Berkely and Los Angeles, USA: University of California Press.

21. Ragin, C. (1987)- The Comparative Method: Moving Beyond Qualitative and Quantitative Strategies. Berkeley and Los Angeles: University of California Press.

22. Rihoux, B., and Ragin, C. C. (2009). Configurational comparative methods: Qualitative comparative analysis (QCA) and related techniques. Thousand Oaks, CA: Sage. 
23. Russel, H. \& Smith A. \& Nicholson, M \& Stewart, B. (2015) - Sport management-principles and application, New York, Routledge;

24. Ruggis, P and Grigorienko (1994) - Cultural meaning systems, intelligence and personality, Personality and intelligence, New York: Cambridge University Press;

25. Quirk, J. and Fort, R. (1992) - The Business of Professional Team Sports, Princeton, Princeton University Press;

26. Schein, E. (2010) - Organizational Culture and Leadership, San Francisco, Jossey- Bas;

27. Schneider, C. Q., \&Wagemann, C. (2010). Standards of good practice in qualitative comparative analysis (QCA) and furzy-sets. Comparative Sociology, 9(3), 397418.

28. Schraw, G. and Moshman, D. (1995) - Metacognitive theories; Educational Psychology Review 7: 351-71;

29. Schroeder, P.J. (2010) - Changing team culture: the perspectives of ten successful head coaches, Journal of Sport Behaviour;

30. Sternberg, R. J. and Detteman D.K. (1998) - What is intelligence?, Norwood, N.J. Ablex;

31. Thiem, A. and Dusa, A. (2013) - Boolean Minimization in Social Science Research: A Review of Current Software for Qualitative Comparative Analysis (QCA)". Social Science Computer Review 31(4), 505-521;

32. Thorndike, E.L. (1920) - Intelligence and its uses, Harpers Magazine 140;

33. Triandis, H.C. (1994) - Culture and social behaviour, New York: McGraq-Hill;

34. Westerbeek, H.M. \& Smith, A.C.T. (2003) - Sport Business in the Global Marketplace, London, Palgrave, Macmillan;

35. Woodside, A. G. (2010). Case study research: Theory, methods and practice: Theory, methods, practice. Bingley, UK: Emerald Group Publishing. 


\section{Self-assessment of football players' Cultural Intelligence skills}

Scale: 1 - not at all; 2 - to a small extent; 3 - to a moderate extent; 4 - to a great extent; 5 - to a very great extent

Your names will be confidential and will not be integrated in the research report! Thank you for your contribution!

1. I am conscious of the cultural knowledge I use when interacting with people with different cultural backgrounds.

not at all 12345 to a very great extent

2. I adjust my cultural knowledge as I interact with people from a culture that is unfamiliar to me.

not at all 12345 to a very great extent

3. I am conscious of the cultural knowledge I apply to cross-cultural interactions.

not at all 12345 to a very great extent

4. I check the accuracy of my cultural knowledge as I interact with people from different cultures.

not at all 12345 to a very great extent

5 . I know the legal and economic systems of other cultures.

not at all 12345 to a very great extent

6. I know the rules (e.g., vocabulary, grammar) of other languages.

not at all 12345 to a very great extent

7. I know the cultural values and religious beliefs of other cultures.

not at all 12345 to a very great extent

8. I know the marriage systems of other cultures.

not at all 12345 to a very great extent

9. I know the arts and crafts of other cultures.

not at all 12345 to a very great extent

10. I know the rules for expressing non-verbal behaviors in other cultures.

not at all 12345 to a very great extent

11. I enjoy interacting with people from different cultures.

not at all 12345 to a very great extent

12. I am confident that I can socialize with locals in a culture that is unfamiliar to me.

not at all 12345 to a very great extent

13. I am sure I can deal with the stresses of adjusting to a culture that is new to me.

not at all 12345 to a very great extent

14. I enjoy living in cultures that are unfamiliar to me.

not at all 12345 to a very great extent

15. I am confident that I can get accustomed to the shopping conditions in a different culture.

not at all 12345 to a very great extent

16. I change my verbal behavior (e.g., accent, tone) when a crosscultural interaction requires it.

not at all 12345 to a very great extent

17. I use pause and silence differently to suit different crosscultural situations.

not at all 12345 to a very great extent

18. I vary the rate of my speaking when a cross-cultural situation requires it.

not at all 12345 to a very great extent

19. I change my non-verbal behavior when a cross-cultural interaction requires it.

not at all 12345 to a very great extent

20. I alter my facial expressions when a cross-cultural interaction requires it.

not at all 12345 to a very great extent

21. How do you perceive the adaptation level to the club where you are playing/played in other country ? not at all 12345 to a very great extent

22. Your nationality:

23. The country where you are playing/played: 